\title{
Renal angina index predicts fluid overload in critically ill children: an observational cohort study
}

Stephen M. Gorga ${ }^{1 *}$, Erin F. Carlton 1,2, Joseph G. Kohne ${ }^{1,2}$, Ryan P. Barbaro ${ }^{1,2}$ and Rajit K. Basu ${ }^{3}$

\begin{abstract}
Background: Fluid overload and acute kidney injury are common and associated with poor outcomes among critically ill children. The prodrome of renal angina stratifies patients by risk for severe acute kidney injury, but the predictive discrimination for fluid overload is unknown.

Methods: Post-hoc analysis of patients admitted to a tertiary care pediatric intensive care unit (PICU). The primary outcome was the performance of renal angina fulfillment on day of ICU admission to predict fluid overload $\geq 15 \%$ on Day 3.

Results: $77 / 139$ children (55\%) fulfilled renal angina (RA+). After adjusting for covariates, RA+ was associated with increased odds of fluid overload on Day 3 (adjusted odds ratio (aOR) 5.1, 95\% Cl 1.23-21.2, $p=0.025$, versus RA-). RAresulted in a $90 \%$ negative predictive value for fluid overload on Day 3. Median fluid overload was significantly higher in RA+ patients with severe acute kidney injury compared to RA+ patients without severe acute kidney injury (\% fluid overload on Day 3: $8.8 \%$ vs. $0.73 \%, p=0.002$ ).

Conclusion: Among critically ill children, fulfillment of renal angina was associated with increased odds of fluid overload versus the absence of renal angina and a higher fluid overload among patients who developed acute kidney injury. Renal angina directed risk classification may identify patients at highest risk for fluid accumulation. Expanded study in larger populations is warranted.
\end{abstract}

Keywords: Fluid overload, Acute kidney injury, Renal angina index, Kidney disease: improving global outcomes

\section{Background}

Fluid overload (FO) and acute kidney injury (AKI) are common and both are associated with poor outcomes among critically ill children [1-5]. Over $25 \%$ of all children admitted to a pediatric intensive care unit (PICU) experience AKI and severe AKI is independently associated with a $12 \%$ mortality rate [5]. Similarly, FO occurs in over one-third of critically ill children and it is consistently associated with increased mortality, mechanical

\footnotetext{
*Correspondence: smgorga@med.umich.edu

${ }^{1}$ Department of Pediatrics, University of Michigan Medical School, $1500 \mathrm{E}$.

Medical Center Drive, F-6890, Ann Arbor, Ml 48109, USA

Full list of author information is available at the end of the article
}

ventilation duration, hospital and intensive care unit (ICU) length of stay $[1,2]$. Furthermore, emerging evidence suggests concurrent FO and AKI worsens outcomes significantly [6].

There is no definitive therapy for AKI after it occurs [7]. In the absence of proven restorative therapy, prevention of AKI has been identified as a priority for management of at risk critically ill patients [7]. Identification of these patients appears to be possible using the renal angina (RA) prodrome for AKI risk stratification $[8,9]$. The Renal Angina Index (RAI) is a validated measurement of RA that combines patient-specific risk factors as well as early signs of renal dysfunction $[9,10]$. 
(Figure 1) Scored at $12 \mathrm{~h}$ into a hospitalization course, the RAI can predict the development of severe AKI on Day 3 of hospitalization with a high negative predictive value (NPV) [9-12]. Utilizing the RAI early in a hospitalization to identify patients at risk for severe AKI provides an opportunity for the development of targeted, patient-centered care to prevent AKI.

Similar to AKI, FO after Day 3 of hospitalization is associated with poor outcomes [13-16]. Further, higher peak FO and the rate of accumulation of FO is associated with considerable mortality and morbidity $[1,2]$. Randomized and observational trial data demonstrate consistent benefit of targeting neutral fluid balances in the ICU and clinicians report management aligned with these evidence-based practices [17-21]. Despite this, evidence suggests that in daily practice, clinicians fail to recognize nearly one-third of patients who have significant $\mathrm{FO}$ and patients continue to receive unrecognized levels of fluid administration $[19,22,23]$. This delayed recognition likely contributes to worse outcomes $[14,19]$. Currently, there are no instruments to assist clinicians' identification of patients at risk for the development of significant FO.

While the RAI can identify patients who are at high risk for AKI, its ability to identify patients who are at risk for FO is unknown. We therefore investigated the predictive efficacy of the RAI to identify significant FO among critically ill children after the initial resuscitative period. We hypothesize that RA would be associated with higher FO states on Day 3 after ICU admission.

\section{Methods}

\section{Study population}

A prospective, observational convenience cohort of patients admitted to a PICU at a tertiary care children's hospital from March 2017 through August 2018 was evaluated, as part of a larger study of clinician identification and prediction of multiple organ dysfunction syndrome in children [24]. All patients included in the parent study period had an expected length of stay greater than 2 days at admission determined by a member of the care team as previously described. For our current study, patients were required to have a serum creatinine measurement within $12 \mathrm{~h}$ of ICU admission as well as complete fluid balance data through Day 3 after ICU admission. Patients were also required to have the complete data necessary to determine RAI, including transplant, mechanical ventilation, and vasoactive medication status. Exclusion criteria were death before Day 3, history of stage 5 chronic kidney disease (i.e., estimated glomerular filtration rate [eGFR] $<15 \mathrm{~mL} / \mathrm{min}$ per $1.73 \mathrm{~m}^{2}$ or on maintenance dialysis), kidney transplantation in the last 90 days, incomplete kidney injury information, or patients admitted during the study period but were not part of the parent study. All methods were carried out in accordance with relevant ethics guidelines and regulations and approved by the University of Michigan. The Institutional Review Board (IRB) at the University of Michigan approved this study and because standard of care was not altered in any way, written informed consent was waived for patients.

\section{Data collection}

Patients' medical records were reviewed for creatinine measurements, past medical history, total fluid input and total fluid output. Hourly urine output was recorded by PICU nursing staff per unit protocol. In an effort to minimize false positive identification of oliguria, in patients without urethral catheters, the total output of mixed stool

\begin{tabular}{|c|c|c|c|}
\hline \multicolumn{3}{|l|}{ Risk Strata } & \\
\hline \multicolumn{2}{|l|}{ Risk Criteria } & Score & \\
\hline \multicolumn{2}{|l|}{ Admission to intensive care unit } & 1 & \\
\hline \multicolumn{2}{|c|}{ Solid organ or stem-cell transplantation } & 3 & Risk $x$ injury \\
\hline \multicolumn{2}{|c|}{ Mechanical ventilation or vasoactive support, or both } & 5 & Scores: $1-40$ \\
\hline \multicolumn{3}{|l|}{ Injury Strata } & $\begin{array}{l}\text { Renal angina fulfilled } \\
\text { with renal angina }\end{array}$ \\
\hline Decreased or no change & $\leq 5$ & 1 & index score $\geq 8$ \\
\hline$>1 x-1.49 x$ & $5-10$ & 2 & \\
\hline $1.5 x-1.99 x$ & $11-15$ & 4 & \\
\hline$\geq 2 x$ & $>15$ & 8 & \\
\hline
\end{tabular}


and urine was used to define urine output as previously published [25]. Additionally, if the patient had an unmeasurable output, it was defined as a normal amount for age by default. To further protect against false positive identification of oliguria in patients without urethral catheters, total urine output was divided over the period of time between instances of output, allowing for normal sleep periods of $>6 \mathrm{~h}$ with no urine output. This protected false identification of stage 1 AKI by Kidney Diseases: Improving Global Outcomes (KDIGO) [26].

\section{Definitions}

Baseline creatinine was measured based on the lowest measured creatinine in the previous 3 months prior to hospitalization [27-29]. If the patient was hospitalized for the last 3 months prior to PICU admission, the lowest creatinine measurement more than 1 month prior to PICU admission was used. If this measurement was not available, baseline creatinine was imputed using age dependent calculations with the assumption of a glomerular filtration rate (GFR) of $120 \mathrm{ml} / \mathrm{min} / 1.73 \mathrm{~m}^{2}$, as previously published [29]. We utilized KDIGO staging criteria to define and classify AKI [26]. The worst stage achieved by serum creatinine or urine output was used to classify kidney injury stage. Severe acute kidney injury was defined as stage 2 or worse.

The renal angina index was determined after $12 \mathrm{~h}$ on the day of ICU admission as previously described, combining the risk and injury scores [9]. (Figure 1) A RAI score of 8 or more is considered fulfilment of renal angina $(\mathrm{RA}+)$ based on derivation and validation studies $[9,10]$.

Hourly FO was determined using intake and output. Because percent FO is part of the definition of RAI, cumulative percent FO started at $12 \mathrm{~h}$ after ICU admission, after RAI fulfilment. All subjects were normalized to $0 \%$ FO after RAI calculation and FO was calculated thereafter. Cumulative FO was then calculated every $12 \mathrm{~h}$ through $96 \mathrm{~h}$ according to previously published definitions [14]:

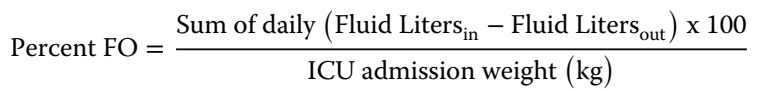

\section{Outcomes}

The primary outcome was the amount of FO at Day 3 after ICU admission. Due to anticipated nonparametric data, FO as an outcome for regression models was dichotomized at $15 \%$ in order to harmonize multiple previously published definitions, accepted published FO data, and recent consensus statements regarding $\mathrm{FO}$ in various critically ill populations of children $[1,14,30]$. Secondary outcomes included differences in FO at $12 \mathrm{~h}$ increments through Day 3, as this is seen as clinically relevant time points for assessment and intervention after the period of resuscitation [7].
Furthermore, assessment of the predictive characteristics of RAI for severe AKI were explored. Given that we investigated the predictive characteristics of RAI for both AKI and FO, and these states can exist together or separately, patients were further characterized into 4 discrete phenotypes at Day 3 based on the presence or absence of $\mathrm{FO}$ and $\mathrm{AKI}$ : 1) $\mathrm{FO}+/ \mathrm{AKI}+$, 2) $\mathrm{FO}-/ \mathrm{AKI}+$,3) $\mathrm{FO}+/$ AKI-, and 4) FO-/AKI- [6]. Finally, we also investigated included the association of FO with ICU length of stay, hospital length of stay, renal replacement therapy utilization, and mortality at 30 days.

\section{Statistical analysis}

Statistical analysis was performed using Stata 16 (StataCorp, LLC, College Station, TX, USA). Categorical data are presented as number and percentages and compared by $x^{2}$ or Fisher's exact test. Continuous data are presented as medians and interquartile ranges (IQR), as we anticipated non-normally distributed data, and compared using the Mann-Whitney test. Repeated admissions were included and considered as a separate, discrete risk of developing AKI. We used bivariate and multivariate logistic models to correct for significant covariate effects and identify independent associations with outcomes. All bivariate associations carrying associations with $p<0.15$ were included as multivariate model terms. A $p$ value $\leq 0.05$ was considered significant.

\section{Results}

\section{Fluid overload}

Of 410 children in the initial data collection, 139 (33.9\%) met criteria for inclusion (Fig. 2). Seventy-seven of 139 (55\%) children fulfilled RA criteria (RA+) (Table 1). Compared to the absence of RA (RA-), a higher proportion of RA+ had FO on Day 3 (27\% vs. 10\%, $p=0.009$ ). This finding remained significant after correcting for severity of illness, age, mechanical ventilator status, transplant status, CRRT receipt, and presence of severe AKI (adjusted odds ratio (aOR) 5.1, 95\% CI 1.23-21.2, $p=0.025)$. FO developed in 27/139 (19.4\%) (Table 2). The negative predictive value of RA+ for FO Day 3 was 90.3\% (80.1-96.4\%) with an area under the ROC curve (AUROC) of 0.64 (0.55-0.73) (Supplemental Table 1).

\section{Acute kidney injury}

Severe AKI developed in 33/139 (23.7\%) children (Table 3). RA+ was associated with risk of both Day 3 severe AKI (relative risk (RR) 4.5; 95\% CI 1.85-10.99, $p=0.001$ ) and Day 3 all stage AKI (RR 2.6, 95\% CI 1.50$4.55, \mathrm{p}=0.001)$. The negative predictive value $\mathrm{RA}+$ to predict severe AKI at Day 3 was 91.9\% (82.2-97.3\%), with an AUROC of 0.69 (0.62-0.77) (Supplemental Table 1). RA+ was also associated with increased renal 


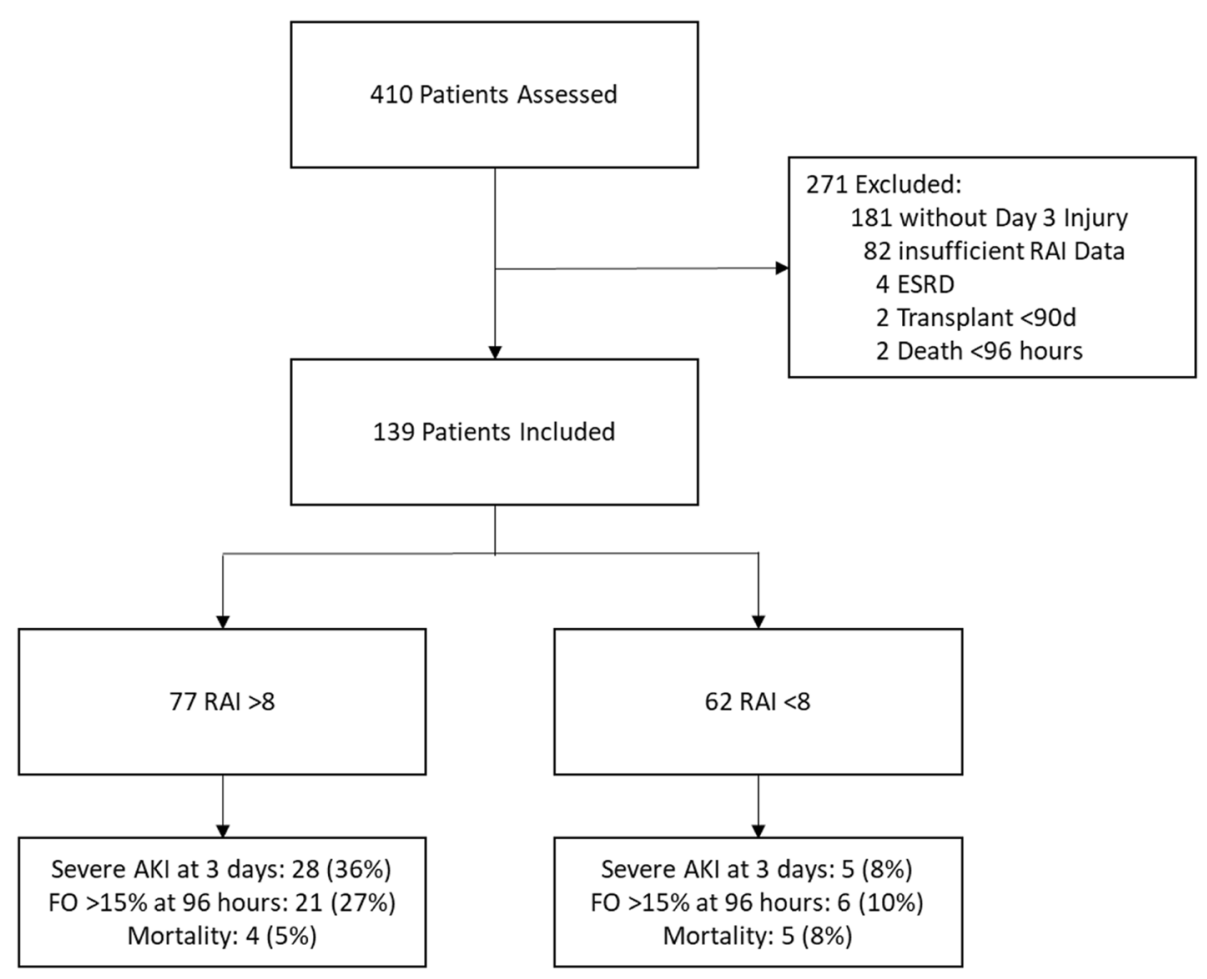

Fig. 2 Participant Inclusion. Data are n(\%). AKI: Acute kidney injury; ESRD: End Stage Renal Disease; RAl: Renal angina index; FO: Fluid overload

replacement therapy (RRT) use, but not with mortality, ICU, or hospital length of stay (Table 1).

\section{Cumulative fluid trajectories}

In order to evaluate fluid trajectories among patients at risk for severe AKI by RA+, median FO\% between patients who developed AKI were compared to those who did not. Median values were compared every $12 \mathrm{~h}$ from RAI scoring (Fig. 3) (Supplemental Table 2). Among RA+ patients, 28/77 (36\%) developed severe AKI on Day 3. Median FO\% was significantly higher among those who developed severe AKI on Day 3 compared to those who did not at each timepoint starting at $36 \mathrm{~h}(4.5 \%$ vs. $2.3 \%, p=0.022)$ through $96 \mathrm{~h}$ ( $8.8 \%$ vs. $0.73 \%, p=0.002)$ (Fig. 3A) (Supplemental Table 3 ). Among RA- patients, 5 of 62 (8\%) developed severe AKI at Day 3. Fluid trajectories were not statistically different at any time point through $96 \mathrm{~h}$ between the two groups (3.7\% severe AKI vs. 3.7\% no severe AKI, $p=0.77$ ) (Fig. 3B) (Supplemental Table 4). Among RA+ patients, FO at $96 \mathrm{~h}$ was independently associated with CRRT use and hospital length of stay, but not ICU length of stay or mortality at 30 days (Supplemental Table 5).

\section{Fluid overload and acute kidney injury phenotypes}

Four possible phenotypic states exist based on the presence or absence of FO and AKI. (Table 4). On Day 3,
15/139 (10.8\%) patients had FO without AKI, 21/139 (15.1\%) patients had AKI without FO, and 12/139 (8.6\%) had both. RA+ conferred a negative predictive value for the phenotype development of $90.3 \%$ (80.1-96.4), 91.9\% (82.2-97.3), and $100 \%(94.2-100 \%)$, respectively. The probability of Day $3 \mathrm{FO}+$ for RA+ patients with AKI (RA+/AKI+) was $42.9 \%(12 / 28)$ compared to $18.4 \%$ (9/49) for RA+/AKI-. (Figure 4) Probability of Day 3 FO+ for all RA- patients was 9.6\% (6/62). No patients who were RA- developed both FO and AKI. Compared to RA-, a significantly higher proportion of RA+ developed the $\mathrm{FO}+/ \mathrm{AKI}+$ phenotype (0/62 vs. $12 / 77,16 \%$, $p=0.001)$. Similarly, compared to $\mathrm{RA}+$, a significantly higher proportion of RA- patients developed the FO-/ AKI- phenotype $(40 / 77,52 \%$ vs $51 / 62,82 \%, p<0.001)$ (Supplemental Table 6).

\section{Discussion}

In this analysis of critically ill children, renal angina fulfillment was independently associated with the development of FO at Day 3 after ICU admission. Additionally, fluid accumulation was higher among those children who fulfilled RA criteria and developed severe AKI compared to those who did not develop severe AKI. This difference was not seen among patients who did not fulfill RA criteria, which may suggest an 
Table 1 Renal angina fulfillment, patient demographics, and outcomes

\begin{tabular}{|c|c|c|c|c|}
\hline Demographics & $\begin{array}{l}\text { All Patients } \\
N=139\end{array}$ & $\begin{array}{l}\mathrm{RA}- \\
N=62\end{array}$ & $\begin{array}{l}\mathrm{RA}+ \\
N=77\end{array}$ & $P$-value \\
\hline Male & 68 (48.9\%) & 35 (56\%) & $33(43 \%)$ & 0.11 \\
\hline Age (y) & $6(1.33-12.33)$ & $6(1.17-13)$ & $6(1.4-11)$ & 0.57 \\
\hline PRISM III & $6(3-11)$ & $3(1-7)$ & $9(4-13)$ & $<0.001$ \\
\hline Mechanical Vent & 73 (52.5\%) & $20(32 \%)$ & $53(69 \%)$ & $<0.001$ \\
\hline CRRT & $11(7.9 \%)$ & $1(2 \%)$ & $10(13 \%)$ & 0.014 \\
\hline Transplant & $9(6.5 \%)$ & $0(0 \%)$ & $9(12 \%)$ & 0.005 \\
\hline \multicolumn{5}{|l|}{ Day 3 AKI Status } \\
\hline None & 88 (63.3\%) & $50(81 \%)$ & $38(49 \%)$ & $<0.001$ \\
\hline Stage 1 & 18 (12.9\%) & $7(11 \%)$ & $11(14 \%)$ & 0.60 \\
\hline Stage 2 & $13(9.4 \%)$ & $2(3 \%)$ & $11(14 \%)$ & 0.026 \\
\hline Stage 3 & 20 (14.4\%) & $3(5 \%)$ & $17(22 \%)$ & 0.004 \\
\hline Any Stage AKI & 51 (36.7\%) & $12(19 \%)$ & $39(51 \%)$ & $<0.001$ \\
\hline Severe AKI & 33 (23.7\%) & $5(8 \%)$ & $28(36 \%)$ & $<0.001$ \\
\hline Day 3 FO $\geq 15 \%$ & 27 (19.4\%) & $6(10 \%)$ & $21(27 \%)$ & 0.009 \\
\hline ICU LOS & $6(3-11)$ & $5.5(3-10)$ & $6(3-12)$ & 0.92 \\
\hline Hospital LOS & $12(7-23)$ & $11(6-21)$ & $15.5(8-31.5)$ & 0.19 \\
\hline Mortality & $9(6.5 \%)$ & $5(8 \%)$ & $4(5 \%)$ & 0.49 \\
\hline
\end{tabular}

Data are presented as median (IQR) for continuous measures, and $\mathrm{n}(\%)$ for categorical measures

$R A I$ - Renal Angina Index negative, $R A I+$ Renal angina index positive, $P R I S M$ III Pediatric risk of mortality 3, CRRT Continuous renal replacement therapy, AKI Acute kidney injury, stages defined by Kidney Disease: Improving Global Outcomes (KDIGO) criteria, ICU Intensive care unit. LOS: Length of stay
Table 3 Severe Acute Kidney Injury at Day 3, patient demographics, characteristics, and outcomes

\begin{tabular}{lllll}
\hline Demographics & All Patients & No Severe AKI & Severe AKI & P-value \\
& $\mathbf{N = 1 3 9}$ & $\mathbf{N = 1 0 6}$ & $\mathbf{N = 3 3}$ & \\
\hline Male & $68(48.9 \%)$ & $51(48.1 \%)$ & $17(51.5 \%)$ & 0.73 \\
Age (y) & $6(1.33-12.33)$ & $6(1.17-12.3)$ & $6(1.75-13)$ & 0.67 \\
PRISM III & $6(3-11)$ & $5(2-9)$ & $12(7-19)$ & $<0.001$ \\
Mechanical Vent & $73(52.5 \%)$ & $50(47.2 \%)$ & $23(69.7 \%)$ & 0.024 \\
CRRT & $11(7.9 \%)$ & $1(0.9 \%)$ & $10(30.3 \%)$ & $<0.001$ \\
Transplant & $9(6.5 \%)$ & $5(4.7 \%)$ & $4(12.1 \%)$ & 0.13 \\
RA+ & $77(55.3 \%)$ & $49(46.2 \%)$ & $28(84.8 \%)$ & $<0.001$ \\
Day 3 FO $\geq 15 \%$ & $27(19.4 \%)$ & $15(14.2 \%)$ & $12(36.4 \%)$ & 0.005 \\
ICU LOS & $6(3-11)$ & $5(3-10)$ & $8(4-13)$ & 0.13 \\
Hospital LOS & $12(7-23)$ & $11(6-20)$ & $22(9-50.5)$ & 0.008 \\
Mortality & $9(6.5 \%)$ & $5(4.7 \%)$ & $4(12.1 \%)$ & 0.13 \\
\hline
\end{tabular}

Data are presented as median (IQR) for continuous measures, and $\mathrm{n}(\%)$ for categorical measures

RAI- Renal Angina Index negative, RAI+ Renal angina index positive, $P R I S M$ III Pediatric risk of mortality 3, CRRT Continuous renal replacement therapy, AKI Acute kidney injury, stages defined by Kidney Disease: Improving Global Outcomes (KDIGO) criteria, ICU Intensive care unit. LOS: Length of stay
Table 2 Fluid overloaded $\geq 15 \%$ at Day 3, patient demographic characteristics, and outcomes

\begin{tabular}{lllll}
\hline Demographics & All Patients & $\mathbf{F O}<\mathbf{1 5 \%}$ & $\mathbf{F O} \geq \mathbf{1 5 \%}$ & $\boldsymbol{P}$-value \\
& $\mathbf{N = 1 3 9}$ & $\mathbf{N = 1 1 2}$ & $\mathbf{N = \mathbf { 2 7 }}$ & \\
\hline Male & $68(48.9 \%)$ & $57(50.9 \%)$ & $11(40.7 \%)$ & 0.34 \\
Age (y) & $6(1.33-12.33)$ & $6.745(2-13)$ & $1.4(0.42-7)$ & 0.002 \\
PRISM III & $6(3-11)$ & $5(2.5-10)$ & $9(3-16)$ & 0.077 \\
Mechanical Vent & $73(52.5 \%)$ & $60(53.6 \%)$ & $13(48.1 \%)$ & 0.61 \\
CRRT & $11(7.9 \%)$ & $1(0.9 \%)$ & $10(37.0 \%)$ & $<0.001$ \\
Transplant & $9(6.5 \%)$ & $6(5.4 \%)$ & $3(11.1 \%)$ & 0.28 \\
Day 3 AKI Status & & & & \\
$\quad$ None & $88(63.3 \%)$ & $75(67.0 \%)$ & $13(48.1 \%)$ & 0.069 \\
$\quad$ Stage 1 & $18(12.9 \%)$ & $16(14.3 \%)$ & $2(7.4 \%)$ & 0.34 \\
Stage 2 & $13(9.4 \%)$ & $11(9.8 \%)$ & $2(7.4 \%)$ & 0.70 \\
Stage 3 & $20(14.4 \%)$ & $10(8.9 \%)$ & $10(37.0 \%)$ & $<0.001$ \\
Any Stage AKI & $51(36.7 \%)$ & $37(33.0 \%)$ & $14(51.9 \%)$ & 0.069 \\
$\quad$ Severe AKI & $33(23.7 \%)$ & $21(18.8 \%)$ & $12(44.4 \%)$ & 0.005 \\
RA+ & $77(55.3 \%)$ & $56(50.0 \%)$ & $21(77.8 \%)$ & 0.009 \\
ICU LOS & $6(3-11)$ & $6(3-10)$ & $6(3-19)$ & 0.28 \\
Hospital LOS & $12(7-23)$ & $11(6-20)$ & $29(10-67)$ & 0.003 \\
Mortality & $9(6.5 \%)$ & $7(6.3 \%)$ & $2(7.4 \%)$ & 0.83 \\
\hline Da are & & &
\end{tabular}

Data are presented as median (IQR) for continuous measures, and $\mathrm{n}(\%)$ for categorical measures

$R A$ - Renal Angina Index negative, $R A+$ Renal angina index positive, $P R I S M$ III Pediatric risk of mortality 3, CRRT Continuous renal replacement therapy, AKI Acute kidney injury, stages defined by Kidney Disease: Improving Global Outcomes (KDIGO) criteria, ICU Intensive care unit. LOS Length of stay

opportunity to identify patients at highest risk of fluid accumulation.

The RAI has the ability to discriminate critically ill children who are at risk of developing severe AKI on Day $3[9,10]$. Here, we confirm and extend these findings to fluid accumulation, with children fulfilling RAI criteria having over 5 times odds of developing FO. FO states are common among critically ill children and are associated with a large burden of resource utilization, morbidity and mortality in multiple pediatric populations $[2,15,16,31-34]$. In particular, we find that all patients who developed the FO+/AKI+ phenotype were RA+. (Figure 4, Supplemental Table 6) Thus, RAI can identify patients at risk for severe AKI and may identify those at risk for fluid overload and therefore may benefit from fluid management strategies.

Continued investigation into the interplay of $\mathrm{FO}$ and AKI has demonstrated both independent and synergistic effects on the outcomes of critically ill children [6]. In our study, RAI was associated with FO status independently of severe AKI, further suggesting independent phenotypes within this population. The ability to predict the development of FO independent of AKI is important for clinicians at the bedside, offering an opportunity 


\section{Panel A: All patients.}

\section{Degree of FO Among All Patients}

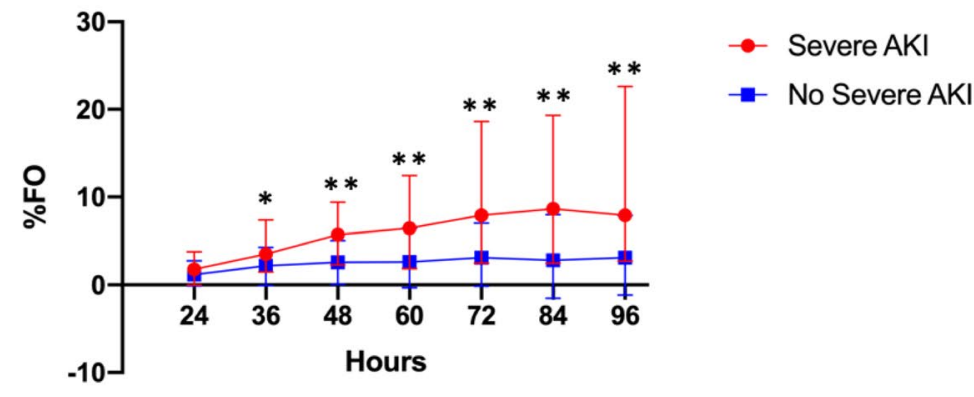

Panel B: RA Negative Patients

\section{Degree of FO Among RA-}

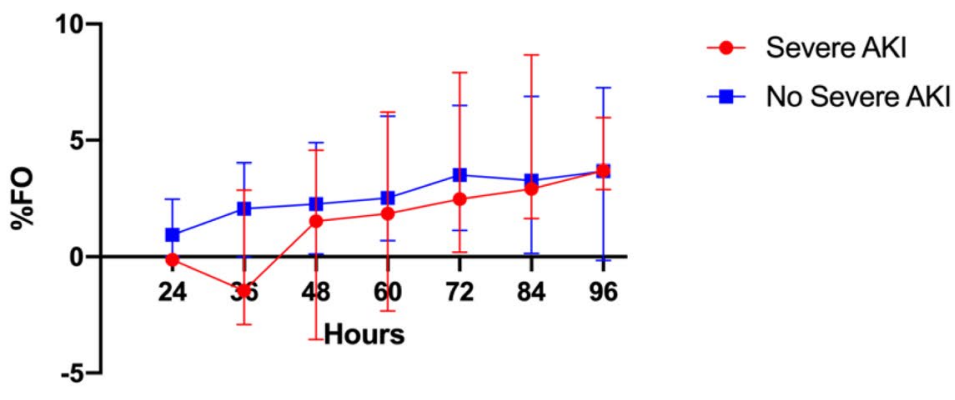

\section{Panel C: RA Positive Patients}

\section{Degree of FO Among RA+}

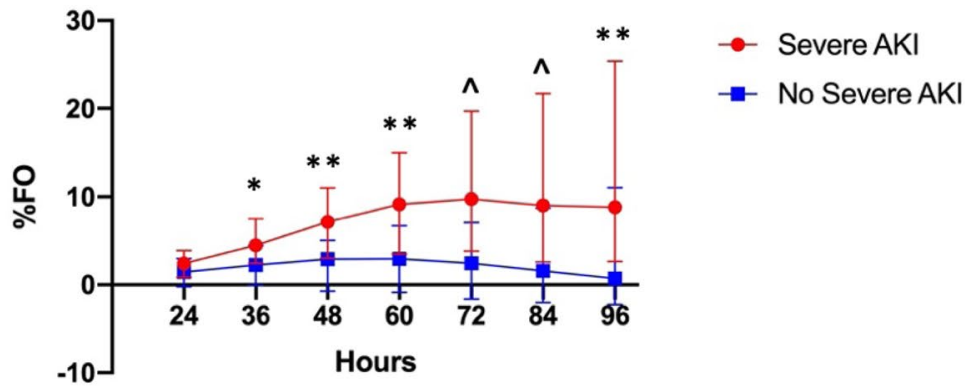

Fig. 3 Cumulative FO percentage among patients over time since ICU admission. AKI: Acute Kidney Injury; FO: Fluid Overload: Hours: Time from ICU admission. ${ }^{*} p<0.05^{* *} p<0.005 \wedge p<0.001$.

to intervene through directed fluid management strategies before excessive FO occurs. An ongoing prospective observational trial combining RAI with urine neutrophil gelatinase associated lipocalin (NGAL) and the furosemide stress test (FST) as a clinical support tool aims to standardize the FST and identify children at risk for FO and AKI [TAKING FOCUS 2, NCT03541785, 2P50 DK096418-06]. Trials in adult populations have demonstrated that active fluid management and deresuscitation may improve outcomes $[17,19]$. With a high negative 
Table 4 Fluid overloaded and acute kidney injury phenotypes and characteristics

\begin{tabular}{|c|c|c|c|c|c|}
\hline Demographics & $\begin{array}{l}\text { FO }+/ \text { AKI }+ \\
N=12\end{array}$ & $\begin{array}{l}\text { FO-/AKI }+ \\
N=21\end{array}$ & $\begin{array}{l}\text { FO+/AKI- } \\
N=15\end{array}$ & $\begin{array}{l}\text { FO-/AKI- } \\
N=91\end{array}$ & $P$-value \\
\hline Male & $4(33 \%)$ & $13(62 \%)$ & $7(47 \%)$ & $44(48 \%)$ & 0.45 \\
\hline Age (y) & $3.5(1.575-12.5)$ & $7(2-13)$ & $0.75(0.25-1.7)$ & $6.49(2-13)$ & 0.003 \\
\hline PRISM III & $14.5(11-25.5)$ & $9(7-16)$ & $4(2-8)$ & $5(2-9)$ & $<0.001$ \\
\hline Mechanical Vent & $9(75 \%)$ & $14(67 \%)$ & $4(27 \%)$ & $46(51 \%)$ & 0.041 \\
\hline CRRT & $9(75 \%)$ & $1(5 \%)$ & $1(7 \%)$ & $0(0 \%)$ & $<0.001$ \\
\hline Transplant & $2(17 \%)$ & $2(10 \%)$ & $17 \%)$ & $4(4 \%)$ & 0.39 \\
\hline \multicolumn{6}{|l|}{ Day 3 AKI Status } \\
\hline None & $0(0 \%)$ & $0(0 \%)$ & $13(87 \%)$ & 75 (82\%) & $<0.001$ \\
\hline Stage 1 & $0(0 \%)$ & $0(0 \%)$ & $2(13 \%)$ & $16(18 \%)$ & 0.084 \\
\hline Stage 2 & $2(17 \%)$ & $11(52 \%)$ & $0(0 \%)$ & $0(0 \%)$ & $<0.001$ \\
\hline Stage 3 & $10(83 \%)$ & $10(48 \%)$ & $0(0 \%)$ & $0(0 \%)$ & $<0.001$ \\
\hline Any Stage AKI & $12(100 \%)$ & $21(100 \%)$ & $2(13 \%)$ & $16(18 \%)$ & $<0.001$ \\
\hline Severe AKI & $12(100 \%)$ & $21(100 \%)$ & $0(0 \%)$ & $0(0 \%)$ & $<0.001$ \\
\hline Day $3 \mathrm{FO} \geq 15 \%$ & $12(100 \%)$ & $0(0 \%)$ & $15(100 \%)$ & $0(0 \%)$ & $<0.001$ \\
\hline ICU LOS & $14.5(9.5-21)$ & $6(3-10)$ & $4(2-6)$ & $6(3-10)$ & 0.018 \\
\hline Hospital LOS & $32.5(24.5-72)$ & $16(7-28)$ & $14(6-61)$ & $11(6-19)$ & 0.003 \\
\hline Mortality & $2(17 \%)$ & $2(10 \%)$ & $0(0 \%)$ & $5(5 \%)$ & 0.31 \\
\hline \multicolumn{6}{|c|}{ RAI Performance of Phenotype Prediction } \\
\hline Sensitivity & $100 \%(73.5-100)$ & $76.2 \%(52.8-91.8)$ & $60 \%(32.3-83.7)$ & $44 \%(33.6-54.8)$ & \\
\hline Specificity & $48.8 \%(39.9-57.8)$ & $48.3 \%(39-57.7)$ & $45.2 \%(36.2-54.3)$ & $22.9 \%(12-37.3)$ & \\
\hline AUROC & $0.74(0.70-0.79)$ & $0.62(0.52-0.73)$ & $0.53(0.39-0.66)$ & $0.33(0.26-0.41)$ & \\
\hline NPV & $100 \%(94.2-100)$ & $91.9 \%(82.2-97.3)$ & $90.3 \%(80.1-96.4)$ & $17.7 \%(9.2-29.5)$ & \\
\hline
\end{tabular}

Data are presented as median (IQR) for continuous measures, and $\mathrm{n}(\%)$ for categorical measures

$R A /$ Renal Angina Index, RA- Renal Angina Index negative, $R A+$ Renal angina index positive, PRISM III Pediatric risk of mortality $3, C R R T$ Continuous renal replacement therapy, AKI Acute kidney injury, stages defined by Kidney Disease: Improving Global Outcomes (KDIGO) criteria, FO Fluid overload > 15\%, ICU Intensive care unit. LOS Length of stay

predictive value of $90 \%$ for predicting FO, RAI may provide an opportunity to identify children early in an ICU course for population enrichment for similar trials evaluating directed fluid management strategies in critically ill children.

In contrast to AKI, early FO treatment and mitigation strategies do exist and are feasible [17, 19, 20, 35-38]. While fluid administration is a mainstay of pediatric resuscitation and support, excessive fluid accumulation is common and often goes unrecognized with nearly one-third of patients with clinical signs and symptoms of FO $\geq 15 \%$ is unnoticed [22, 23, 39]. Major contributions to FO states tend to be from "fluid creep" as opposed to resuscitation fluids early in the ICU course and median fluid exposure exceeds weight-based maintenance on Day 3 of critical illness [22]. Here, we found that fluid accumulation was significantly different among children who developed severe AKI compared to those who did not. This finding was present as early as $36 \mathrm{~h}$ after ICU admission, suggesting an early opportunity to recognize and intervene before significant FO develops. Importantly, this finding was seen among patients who fulfilled RA criteria, but not among those who did not. As such, this discriminatory power of RAI may be helpful in identifying those children most at risk for excessive fluid accumulation at admission.

This study had several limitations. As a retrospective study, all findings are limited to associations as opposed to causality. Importantly, this study does not answer the cause-and-effect nature of AKI and FO. However, it does suggest the possibility to identify children early in an ICU course in a future, prospective way. Secondly, this study did not identify medications which may affect fluid balance or influence development of AKI through nephrotoxic actions. These multiple interactions should be investigated in future, prospective ways. Further, we did not find significant associations with mortality at 30 days. This finding is likely related to low overall mortality and a small cohort with inadequate power to find a difference. However, other patient- and family-centered outcomes, including dialysis receipt and hospital length of stay, were reinforced in this study. The included patients all had an expected length of stay $>48 \mathrm{~h}$, which may suggest these patients were sicker and potentially bias the findings 


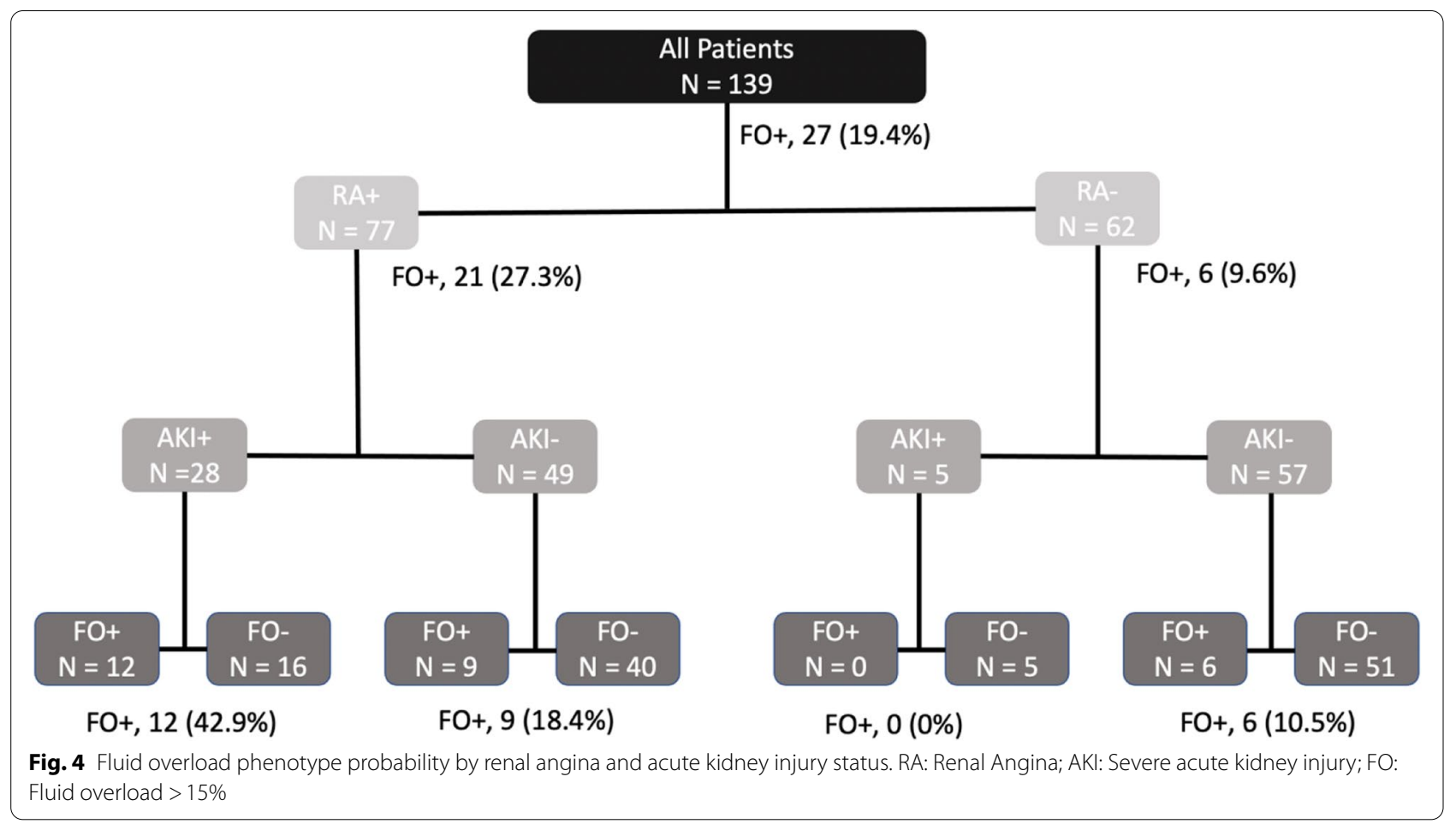

toward the development of AKI and FO. However, as the RAI was used in all patients, this inclusion factor served as a population enrichment strategy. Finally, if a patient did not have a Foley catheter in place, any mixed stool and urine output was classified as "urine output", potentially overestimating urine output and therefore underestimating the rate of oliguria. This may bias the classification of AKI to be less severe than was actually present, potentially weakening or missing important AKI related associations.

\section{Conclusion}

In this study of critically ill children at risk for AKI, we found that RA fulfillment was associated with increased odds of FO at Day 3. Furthermore, we demonstrated that fluid accumulation was different as early as $36 \mathrm{~h}$ after admission among children who went on to develop severe AKI at Day 3 compared to those who did not develop severe AKI. These findings suggest that RAI may identify patients at high risk of developing significant fluid overload.

\section{Abbreviations}

AKI: Acute kidney injury; FO: Fluid overload; PICU: Pediatric intensive care unit; ICU: Intensive care unit; RA: Renal angina; RAI: Renal angina index; NPV: Negative predictive value; OR: Odds ratio; eGFR: Estimated glomerular filtration rate; KDIGO: Kidney diseases: improving global outcomes; IRB: Institutional review board; IQR: Interquartile range; AUROC: Area under the receiver operator characteristic curve.

\section{Supplementary Information}

The online version contains supplementary material available at https://doi. org/10.1186/s12882-021-02540-6.

Additional file 1: Supplemental Table 1. Predictive Characteristics of RAl for $F O \geq 15 \%$. Supplemental Table 2. Median FO\% over time among all patients. Supplemental Table 3. Median FO\% over time among RA+ Patients. Supplemental Table 4. Median FO\% among RAl- patients. Supplemental Table 5. Predictive Characteristics of RAI for Severe AKI. Supplemental Table 6: RAI status of FO/AKI phenotypes.

\section{Acknowledgements}

Not applicable.

\section{Authors' contributions}

SMG, EFC, RKB participated in the study design. SMG, EFC, JGK, RPB, and RKB participated in data analysis and interpretation and contributed important intellectual content during manuscript drafting and revision. All authors have read and approved the final manuscript.

\section{Funding}

Not applicable.

\section{Availability of data and materials}

The data analyzed during this study are available from the corresponding author upon reasonable request.

\section{Declarations}

Ethics approval and consent to participate

This research was approved by the Institutional Review Board at the University of Michigan. Written informed consent from patients was waived by the Institutional Review Board at the University of Michigan. 


\section{Consent for publication \\ Not applicable.}

\section{Competing interests}

The authors declare they have no competing interests.

\begin{abstract}
Author details
'Department of Pediatrics, University of Michigan Medical School, $1500 \mathrm{E}$. Medical Center Drive, F-6890, Ann Arbor, Ml 48109, USA. ${ }^{2}$ Susan B. Meister Child Health Evaluation and Research (CHEAR) Center, University of Michigan, Ann Arbor, MI, USA. ${ }^{3}$ Children's Healthcare of Atlanta/Emory University, Atlanta, GA, USA.
\end{abstract}

\section{Received: 26 May 2021 Accepted: 13 September 2021}

Published online: 11 October 2021

\section{References}

1. Alobaidi R, Morgan C, Basu RK, Stenson E, Featherstone R, Majumdar SR, et al. Association between fluid balance and outcomes in critically ill children: A systematic review and Meta-analysis. JAMA Pediatr. 2018;172:257 https://doi.org/10.1001/jamapediatrics.2017.4540.

2. Alobaidi R, Basu RK, DeCaen A, Joffe AR, Lequier L, Pannu N, et al. Fluid accumulation in critically ill children. Crit Care Med. 2020;48:1034-41. https://doi.org/10.1097/ccm.0000000000004376.

3. Alobaidi R, Morgan C, Goldstein SL, Bagshaw SM. Population-based epidemiology and outcomes of acute kidney injury in critically ill children. Pediatr Crit Care Med. 2020;21:82-91. https://doi.org/10.1097/pcc.00000 00000002128

4. Sutherland SM, Ji J, Sheikhi FH, Widen E, Tian L, Alexander SR, et al. AKI in hospitalized children: epidemiology and clinical associations in a national cohort. Clin J Am Soc Nephro. 2013;8:1661-9. https://doi.org/10.2215/cjn. 00270113.

5. Kaddourah A, Basu RK, Bagshaw SM, Goldstein SL. Epidemiology of acute kidney injury in critically ill children and Young adults. New Engl J Medicine. 2017;376:11-20. https://doi.org/10.1056/nejmoa1611391.

6. Gist KM, Selewski DT, Brinton J, Menon S, Goldstein SL, Basu RK. Assessment of the independent and synergistic effects of fluid overload and acute kidney injury on outcomes of critically ill children. Pediatr Crit Care Med. 2019;1. https://doi.org/10.1097/pcc.0000000000002107.

7. Chawla LS, Bellomo R, Bihorac A, Goldstein SL, Siew ED, Bagshaw SM, et al. Acute kidney disease and renal recovery: consensus report of the acute disease quality initiative (ADQI) 16 workgroup. Nat Rev Nephrol. 2017;13:241-57. https://doi.org/10.1038/nrneph.2017.2.

8. Basu RK, Chawla LS, Wheeler DS, Goldstein SL. Renal angina: an emerging paradigm to identify children at risk for acute kidney injury. Pediatr Nephrol. 2012;27:1067-78. https://doi.org/10.1007/s00467-011-2024-5.

9. Basu RK, Zappitelli M, Brunner L, Wang Y, Wong HR, Chawla LS, et al. Derivation and validation of the renal angina index to improve the prediction of acute kidney injury in critically ill children. Kidney Int. 2014;85:659-67. https://doi.org/10.1038/ki.2013.349.

10. Basu RK, Kaddourah A, Goldstein SL, investigators A study, Akcan-Arikan A, Arnold M, et al. Assessment of a renal angina index for prediction of severe acute kidney injury in critically ill children: a multicentre, multinational, prospective observational study. Lancet Child Adolesc Heal. 2018:2:112-20. https://doi.org/10.1016/s2352-4642(17)30181-5.

11. Huang L, Shi T, Quan W, Li W, Zhang L, Liu X, et al. Assessment of early renal angina index for prediction of subsequent severe acute kidney injury during septic shock in children. BMC Nephrol. 2020;21:358. https:// doi.org/10.1186/s12882-020-02023-0.

12. Ortiz-Soriano V, Kabir S, Granado RC-D, Stromberg A, Toto RD, Moe OW, et al. Assessment of a modified renal angina index for AKI prediction in critically ill adults. Nephrol Dial Transpl. 2021. https://doi.org/10.1093/ndt/ gfab049.

13. Lima L, Menon S, Goldstein SL, Basu RK. Timing of fluid overload and association with patient outcome. Pediatr Crit Care Med. 2020;22:114-24. https://doi.org/10.1097/pcc.0000000000002547.

14. Akcan-Arikan A, Gebhard DJ, Arnold MA, Loftis LL, Kennedy CE. Fluid overload and kidney injury score. Pediatr Crit Care Med. 2017;18:524-30. https://doi.org/10.1097/pcc.0000000000001123.
15. Sinitsky L, Walls D, Nadel S, Inwald DP. Fluid overload at 48 hours is associated with respiratory morbidity but not mortality in a general PICU. Pediatr Crit Care Med. 2015;16:205-9. https://doi.org/10.1097/pcc.00000 00000000318.

16. Li Y, Wang J, Bai Z, Chen J, Wang X, Pan J, et al. Early fluid overload is associated with acute kidney injury and PICU mortality in critically ill children. Eur J Pediatr. 2016;175:39-48. https://doi.org/10.1007/s00431-015-2592-7.

17. Network NH Lung, and Blood Institute Acute Respiratory Distress Syndrome (ARDS) Clinical Trials, Wiedemann HP, Wheeler AP, Bernard GR, Thompson BT, Hayden D, et al. Comparison of two fluid-management strategies in acute lung injury. New Engl J Medicine. 2006;354:2564-75. https://doi.org/10.1056/nejmoa062200.

18. Valentine SL, Sapru A, Higgerson RA, Spinella PC, Flori HR, Graham DA, et al. Fluid balance in critically ill children with acute lung injury. Crit Care Med. 2012;40:2883-9. https://doi.org/10.1097/ccm.0b013e3182 5 bc54d.

19. Silversides JA, Fitzgerald E, Manickavasagam US, Lapinsky SE, Nisenbaum $\mathrm{R}$, Hemmings $\mathrm{N}$, et al. Deresuscitation of patients with iatrogenic fluid overload is associated with reduced mortality in critical illness. Crit Care Med. 2018:46:1600-7. https://doi.org/10.1097/ccm.0000000000003276.

20. Silversides JA, McAuley DF, Blackwood B, Fan E, Ferguson AJ, Marshall JC. Fluid management and deresuscitation practices: A survey of critical care physicians. J Intensive Care Soc. 2020;21:111-8. https://doi.org/10.1177/ 1751143719846442.

21. Hassinger AB, Valentine SL. Self-reported management of IV fluids and fluid accumulation in children with acute respiratory failure. Pediatr Crit Care Med. 2018;19:e551-4. https://doi.org/10.1097/pcc.0000000000 001685.

22. Al-Lawati ZH, Sur M, Kennedy CE, Arikan AA. Profile of fluid exposure and recognition of fluid overload in critically ill children. Pediatr Crit Care Medd. 2020;21:760-6. https://doi.org/10.1097/pcc.0000000000002337.

23. Barhight MF, Nelson D, Chong G, Basu RK, Sanchez-Pinto LN. Non-resuscitation fluid in excess of hydration requirements is associated with higher mortality in critically ill children. Pediatr Res. 2021:1-6. https://doi.org/10. 1038/s41390-021-01456-z.

24. Carlton EF, Close J, Paice K, Dews A, Gorga SM, Sturza J, et al. Clinician accuracy in identifying and predicting organ dysfunction in critically ill children. Crit Care Med. 2020;48:e1012-9. https://doi.org/10.1097/ccm. 0000000000004555.

25. Gorga SM, Carlton EF, Kohne JG, Barbaro RP, Basu RK. Consensus acute kidney injury criteria integration identifies children at risk for long-term kidney dysfunction after multiple organ dysfunction syndrome. Pediatr Nephrol. 2021:1-10. https://doi.org/10.1007/s00467-020-04865-0.

26. Acute Kidney Injury Work Group. Kidney disease: improving global outcomes (KDIGO) KDIGO clinical practice guideline for acute kidney injury. Kidney Int Suppl. 2012;2:1-138. https://doi.org/10.1038/kisup. 2012.2.

27. Alkandari O, Eddington KA, Hyder A, Gauvin F, Ducruet T, Gottesman R, et al. Acute kidney injury is an independent risk factor for pediatric intensive care unit mortality, longer length of stay and prolonged mechanical ventilation in critically ill children: a two-center retrospective cohort study. Crit Care. 2011;15:R146. https://doi.org/10.1186/cc10269.

28. Selewski DT, Cornell TT, Heung M, Troost JP, Ehrmann BJ, Lombel RM, et al. Validation of the KDIGO acute kidney injury criteria in a pediatric critical care population. Intens Care Med. 2014;40:1481-8. https://doi.org/10. 1007/s00134-014-3391-8

29. Hessey E, Ali R, Dorais M, Morissette G, Pizzi M, Rink N, et al. Evaluation of height-dependent and height-independent methods of estimating baseline serum creatinine in critically ill children. Pediatr Nephrol. 2017;32:1953-62. https://doi.org/10.1007/s00467-017-3670-z.

30. Selewski DT, Askenazi DJ, Kashani K, Basu RK, Gist KM, Harer MW, et al. Quality improvement goals for pediatric acute kidney injury: pediatric applications of the 22nd acute disease quality initiative (ADQI) conference. Pediatr Nephrol. 2021:1-14. https://doi.org/10.1007/ s00467-020-04828-5.

31. Alobaidi R, Lequier L. Fluid overload and extracorporeal membrane oxygenation. Pediatr Crit Care Med. 2017;18:1181-2. https://doi.org/10.1097/ pcc.0000000000001357.

32. Bagshaw SM, Brophy PD, Cruz D, Ronco C. Fluid balance as a biomarker: impact of fluid overload on outcome in critically ill patients with acute kidney injury. Crit Care. 2008;12:169. https://doi.org/10.1186/cc6948. 
33. Arikan AA, Zappitelli M, Goldstein SL, Naipaul A, Jefferson LS, Loftis LL. Fluid overload is associated with impaired oxygenation and morbidity in critically ill children. Pediatr Crit Care Med. 2012;13:253-8. https://doi.org/ 10.1097/pcc.0b013e31822882a3.

34. Hazle MA, Gajarski RJ, Yu S, Donohue J, Blatt NB. Fluid overload in infants following congenital heart surgery. Pediatr Crit Care Med. 2013;14:44-9. https://doi.org/10.1097/pcc.0b013e3182712799.

35. Vincent J-L. Fluid management in the critically ill. Kidney Int. 2019;96:527. https://doi.org/10.1016/j.kint.2018.11.047.

36. Ostermann M, Liu K, Kashani K. Fluid management in acute kidney injury. Chest. 2019. https://doi.org/10.1016/j.chest.2019.04.004.

37. Perner A, Prowle J, Joannidis M, Young P, Hjortrup PB, Pettilä V. Fluid management in acute kidney injury. Intens Care Med. 2017;43:807-15. https://doi.org/10.1007/s00134-017-4817-x.
38. Granado RC-D, Mehta RL. Fluid overload in the ICU: evaluation and management. BMC Nephrol. 2016;17:109. https://doi.org/10.1186/ s12882-016-0323-6.

39. Carcillo JA, Davis AL, Zaritsky A. Role of early fluid resuscitation in pediatric septic shock. JAMA. 1991;266:1242-5. https://doi.org/10.1001/jama. 1991.03470090076035

\section{Publisher's Note}

Springer Nature remains neutral with regard to jurisdictional claims in published maps and institutional affiliations.
Ready to submit your research? Choose BMC and benefit from:

- fast, convenient online submission

- thorough peer review by experienced researchers in your field

- rapid publication on acceptance

- support for research data, including large and complex data types

- gold Open Access which fosters wider collaboration and increased citations

- maximum visibility for your research: over $100 \mathrm{M}$ website views per year

At BMC, research is always in progress.

Learn more biomedcentral.com/submissions 